\title{
INVENTÁRIO DA ARBORIZAÇÃO URBANA IMPLANTADA NA DÉCADA DE 60 NO PLANO PILOTO, BRASÍLIA, DF
}

\author{
Roberta Maria Costa e Lima'; Manoel Cláudio Silva Júnior² \\ (recebido em 21.05.2010 e aceito para publicação em 15.12.2010)
}

\section{RESUMO}

A avaliação da arborização nas cidades auxilia no planejamento e na administração das áreas verdes urbanas, assim como na busca de melhores condições de vida para a população citadina. Em Brasília, realizou-se o inventário em 10 superquadras arborizadas na década de 60 , com a condução de censo das árvores, DAP $\geq 5 \mathrm{~cm}$, visando avaliar a composição florística, assim como a utilização de espécies nativas naquele período. Foram amostrados ao todo 4.493 indivíduos pertencentes a 35 famílias, distribuídos em 92 gêneros e 118 espécies. As famílias Fabaceae, Bignoniaceae, Anacardiaceae, Myrtaceae e Malvaceae apresentaram o maior número de espécies utilizadas na arborização na década de 60. As espécies mais frequentes foram Mangifera indica L. (Mangueira), Spathodea campanulata Beauv. (Xixi-de-macaco), Caesalpinia pluviosa DC. (Sibipiruna), Peltophorum dubium (Spreng.) Taub. (Cambuí), Syzygium jambolanum (Lam.) DC. (Jambolão), Persea americana Mill. (Abacateiro), Ceiba speciosa St. Hill (Paineira), Tabebuia ipe (Mart ex K. Schum.) Standl. (Ipê-rosa); Sapindus saponaria L. (Saboneteira) e Caesalpinia leiostachya (Benth.) Duke. (Pau-ferro). A arborização na década de 60 incluiu grande riqueza de espécies com predominância de espécies exóticas.

Palavras-chave: árvores, florística, arborização, riqueza de espécies.

\footnotetext{
${ }^{1}$ Engenheira Florestal, Mestra em Ciências Florestais, Brasília, DF, limroberta@gmail.com

${ }^{2}$ Engenheiro Florestal, PhD em Ecologia Florestal, UnB, Departamento de Engenharia Florestal, Brasília, DF,
} 


\section{INVENTORY OF THE URBAN FORESTRY ADOPTED IN THE 1960S IN BRASILIA'S PILOT PLAN}

\section{ABSTRACT}

The assessment of tree planting in the cities helps the planning and management of urban green areas, as well as the search of better life conditions to the cities' dwellers. In Brasilia, an inventory was made in 10 superblocks with trees planted in the 1960s through the census of the trees $\mathrm{DBH} \geq 5 \mathrm{~cm}$, aiming to assess the floristic composition and the use of native species in that period. A total of 4,493 trees were sampled, which belong to 35 botanical families, 92 genera, and 118 species. The families Fabaceae, Bignoniaceae, Anacardiaceae, Myrtaceae, and Malvaceae represent most of the species used in the tree planting of the 1960s. The most frequent species were Mangifera indica L. (Mango tree), Spathodea campanulata Beauv (African tulip tree), Caesalpinia pluviosa DC. (False brazilwood), Peltophorum dubium (Spreng.) Taub. (Cambuí), Syzygium jambolanum (Lam.) DC. (Jambolan), Persea americana Mill. (Avocado tree), Ceiba speciosa St. Hill (Silk floss tree), Tabebuia ipe (Mart ex K. Schum.) Standl. (Pink Ipê); Sapindus saponaria L. (Wingleaf soapberry), and Caesalpinia leiostachya (Benth.) Duke (Iron-wood). Brasilia's tree planting in the 1960s had a large variety of species, predominantly exotic species.

Keywords: trees, floristics, tree planting, species richness. 


\section{INTRODUÇÃO}

O conhecimento e a análise das estruturas das cidades e suas funções, através das óticas econômica, social e ambiental são pré-requisitos básicos para o planejamento e administração das áreas urbanas, na busca de melhores condições de vida para os seus habitantes (ROCHA et al., 2004). Neste sentido, a utilização e valorização dos recursos florestais em centros urbanos, a sua importância, benefícios e metodologias atualmente são temas de vários estudos como os realizados por Jacinto (2001), Kurihara et al. (2005) e Silva et al. (2007).

A arborização urbana representa para a maioria das cidades seu maior investimento em vegetação e acaba por influenciar o clima ao atenuar o calor do sol, melhorar a qualidade do ar e promover o embelezamento dos locais onde as pessoas vivem e trabalham (SPIRN, 1995).

Planejada por Lúcio Costa, dispondo de amplos espaços livres obedecendo aos padrões urbanísticos da década de 50, frutos das concepções modernistas (ALENCAR e LIMA, 2001), Brasília é capital que se destaca pela arborização. A cidade dispõe de grande quantidade de espaços quase sempre densamente arborizados, fato que confere características marcantes à sua paisagem urbana (SILVA, 2003).

A concepção naturalista adotada no Modernismo como modelo para o tratamento dos espaços livres, pressupunha que seu uso levasse em consideração as restrições e potencialidades de cada sítio, resultando em tratamento mais natural da paisagem que demandasse menores investimentos para implantação e manutenção (SILVA, 2003).

No entanto, à medida que Brasília ia sendo edificada a paisagem natural ia dando lugar a outra completamente diferente. Não havia como fugir do tradicionalismo e se repetia em pleno complexo vegetacional do cerrado o que havia ocorrido na concepção de outras urbes erguidas em meio à Caatinga, Floresta Amazônica, Floresta Atlântica (ROMERO, 2001).

Após a retirada da vegetação nativa tornou-se então urgente, para inauguração da nova capital, a reintrodução da vegetação no meio urbano (FERRARA, 2000). A paisagem desnuda e com poucos remanescentes nativos não garantia sombra e não preenchia as áreas destinadas a bosques e aos espaços verdes definidos no projeto da nova cidade (ALENCAR e LIMA, 2001).

Tendo em vista o Relatório do Plano Piloto (1957) de Lúcio Costa, o qual enfatizava a importância da arborização dentro do conceito de Brasília como cidade-parque, foram introduzidas plantas provenientes de outras regiões do Brasil e do mundo sem qualquer

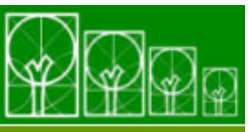

$\mathbf{S} \cdot \mathbf{B} \cdot \mathbf{A} \cdot \mathbf{U}$ Soc. Bras. de Arborização Urbana 
preocupação em resguardar as características do ecossistema existente. As espécies escolhidas foram as largamente utilizadas em outras cidades brasileiras (LIMA, 2003).

Com o passar dos anos começaram os problemas resultantes da decisão de usar espécies exóticas em larga escala, como exsudações nos troncos, amarelecimento, queda das folhas e morte de grande número de indivíduos (TEIXEIRA NETO e RODRIGUES, 1975). A falta de adaptação de algumas espécies acarretou na década de 70 o perecimento de 50.000 árvores adultas, gerando críticas da opinião pública e dos meios de comunicação (ALENCAR e LIMA, 2001).

A solução técnica adotada foi utilizar na arborização espécies do Cerrado mais adaptadas às condições de solos e clima. Os procedimentos utilizados para a seleção de novas espécies foram e têm sido a identificação destas na vegetação nativa regional; a possibilidade de coleta de sementes das matrizes arbóreas selecionadas; a produção de mudas em viveiro; e o plantio destas nas áreas verdes da cidade para avaliação de seu comportamento (GONZÁLES et al., 2001).

Segundo Silva (2003), a utilização de espécies nativas fortaleceu-se e se mantém até os dias de hoje, quando se discute a possibilidade do emprego das mesmas espécies arbóreas que existiam originalmente no Plano Piloto. A recuperação da flora original pode trazer diversas vantagens, tais como dar identidade à arborização da cidade, melhorar as taxas de sobrevivência no plantio, promover maior longevidade às árvores no meio urbano, diminuir custos de manutenção, além da possibilidade de proporcionar contato da população local com a vegetação nativa. Segundo a UNESCO (2002), o Plano Piloto foi implantado em área com vegetação original de cerrado sentido restrito e cerradão.

Para o monitoramento sistemático da cobertura florestal das cidades a execução de avaliações da cobertura vegetal constitui-se num elemento básico, permitindo, consequentemente, maior eficiência na tomada de decisões no tocante à política, legislação e sistemas de manejo estabelecidos (SENNA et al., 2001).

Desta forma, o presente trabalho visou avaliar a composição florística dos primeiros plantios na cidade, através do levantamento das árvores em dez superquadras arborizadas na década de 60.

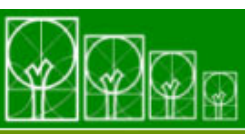

$\mathbf{S} \cdot \mathbf{B} \cdot \mathbf{A} \cdot \mathbf{U}$ Soc. Bras. de Arborização Urbana 


\section{MATERIAIS E MÉTODOS}

\section{Descrição da área de estudo}

O estudo foi realizado no Plano Piloto de Brasília, que engloba as Asas Sul e Norte, e juntas somam 14,3 quilômetros de extensão e têm como via principal o Eixo Rodoviário, formado por pista principal com seis faixas, e eixos auxiliares separando as quadras residenciais numeradas com as centenas 200 e 400, no lado leste, e 100 e 300, no lado oeste, perfazendo um total de 60 superquadras na Asa Sul e 60 superquadras na Asa Norte (Figura 01).

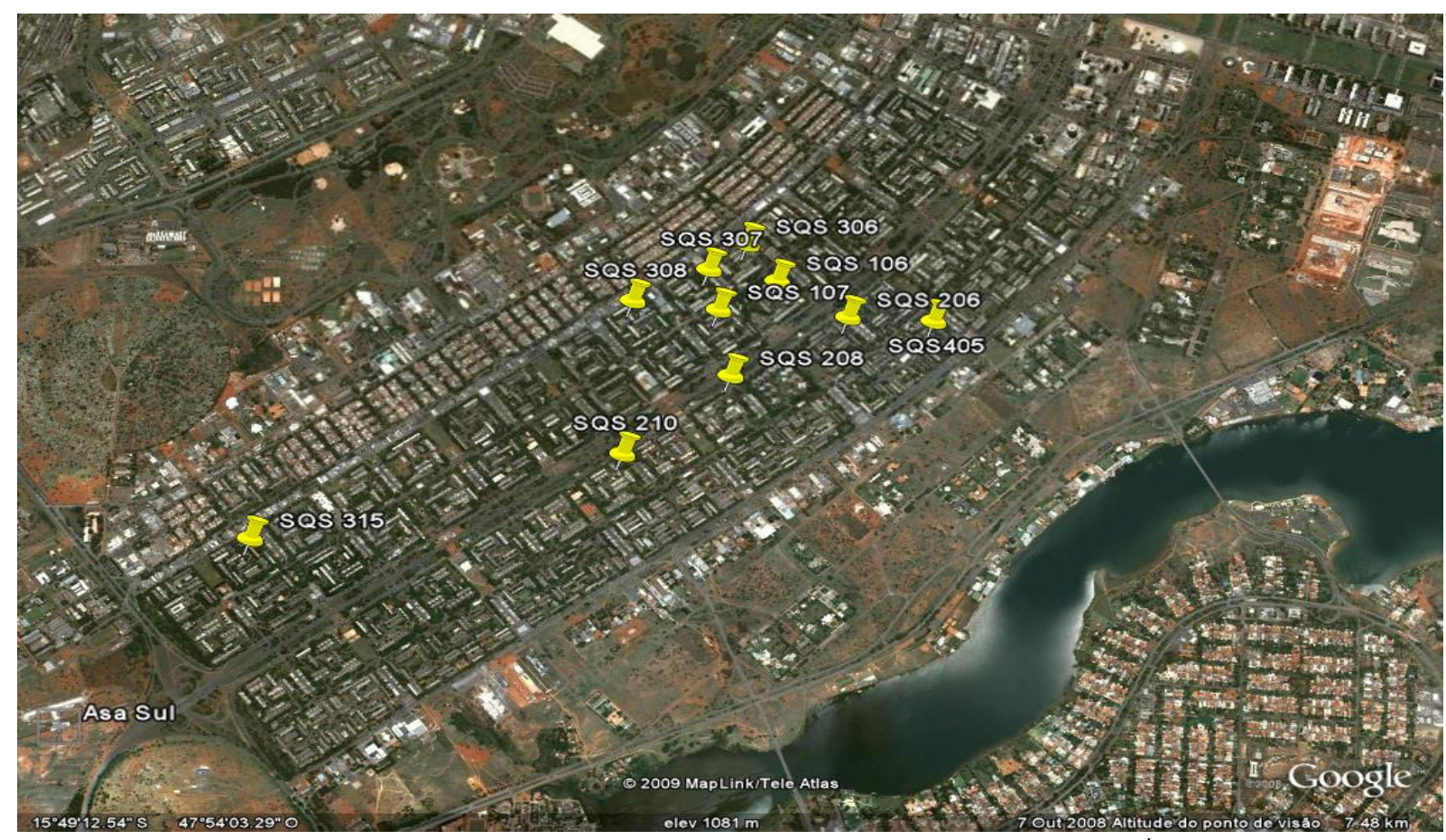

Fonte: Google Earth / Source: Google Earth.

FIGURA 1 - Vista aérea das 10 superquadras inventariadas na Asa Sul, do Plano Piloto de Brasília, arborizadas na década de 60.

FIGURE 1 - Aerial view of the 10 superblocks where the inventory of trees was made, at the South Wing of Brasilia's Pilot Plan - trees planted in the 1960s.

A área total de cada superquadra corresponde a um quadrado de $250 \mathrm{~m}$ de lado, perfazendo um total de $62.500 \mathrm{~m}^{2}$. O emolduramento é uma faixa de $25 \mathrm{~m}$ de largura e corresponde ao anel arborizado que circula as superquadras (CÉSAR, 2003).

O clima da região corresponde ao tipo Cwa da classificação Köppen, tropical de altitude (RIBEIRO e WALTER, 2008), apresentando duas estações bem distintas, uma chuvosa, 
novembro a abril, e outra seca de maio a outubro. O clima pouco ameno é responsável pelo alto grau de intemperização dos solos e por sua baixa fertilidade natural, que, apesar de serem profundos, apresentam restrições quanto à disponibilidade de nutrientes e grandes quantidades de alumínio e ferro disponíveis (UNESCO, 2002).

A cidade de Brasília, com relevo plano a suave ondulado e o tipo de solo (Latossolo), possuía como cobertura vegetal predominante o cerrado sentido restrito, o cerradão e o campo cerrado, conforme constatado em parques e reservas naturais e de áreas ainda não construídas da cidade que mantêm a vegetação remanescente (JACINTO, 2001) e por mapas da vegetação do DF em 1954 (UNESCO, 2002).

\section{Coleta de dados}

O processo de análise da arborização no Plano Piloto iniciou-se com pesquisas documentais nos registros da empresa responsável pelos projetos e plantios na cidade, a Companhia Urbanizadora da Nova Capital, NOVACAP, realizados ao longo dos anos, além de consulta nas literaturas disponíveis sobre o histórico da Arborização de Brasília (CÉSAR, 2003; LIMA, 2003; SILVA 2003) e consultas ao Arquivo Público do Distrito Federal. Desta forma, mediante sorteio, foram definidas as superquadras anotadas na Figura 1: SQS 106, 107, 206, 208, 210, 306, 307, 308, 315 e 405.

Em cada superquadra selecionada foi realizado o levantamento, tendo sido considerado árvores os indivíduos com tronco único, sustentação própria e diâmetro à altura do peito, $\mathrm{DAP} \geq 5 \mathrm{~cm}$. Foram incluídos indivíduos com troncos perfilhados por rebrota apenas para as espécies reconhecidamente arbóreas. O levantamento excluiu palmeiras e arbustos. Esta decisão foi tomada devido a dificuldade encontrada na identificação das espécies de palmeiras e pela profusão de arbustos incluídos pelos moradores nas áreas residenciais.

No entender de Rocha et al. (2004), para se conhecer a arborização urbana é necessária a condução de inventários, pois os dados obtidos irão auxiliar no planejamento e manejo da arborização. De acordo com Milano (1994), o sistema de amostragem a ser adotado dependerá das características da cidade, dos objetivos da avaliação e dos custos do trabalho. Os censos, que incluem a enumeração de todos os indivíduos na área de estudo, têm custo elevado e demandam tempo maior, só se justificam nas avaliações de pequenas áreas ou comunidades (SILVA et al., 2007).

A coleta de dados em campo iniciou-se no mês de março de 2008 e finalizou-se em dezembro de 2008. No processo de identificação, cada indivíduo foi localizado em croquis específicos para cada superquadra. Todas as espécies foram descritas através do

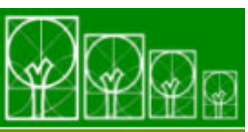

$\mathbf{S} \cdot \mathbf{B} \cdot \mathbf{A} \cdot \mathbf{U}$ Soc. Bras. de Arborização Urbana 
preenchimento de fichas dendrológicas. Estes dados foram usados na elaboração de chaves dendrológicas, procedimento científico e didático que possibilita o aperfeiçoamento profissional de quem a preenche, além de facilitar a identificação das espécies por profissionais, usuários e leigos. Estas chaves dendrológicas serão publicadas em manual de identificação de árvores plantadas em Brasília.

Quando não foi possível o reconhecimento das espécies em campo, foram coletadas amostras de material botânico disponível como: folhas, flores e frutos, para a identificação no herbário da Universidade de Brasília (UnB) ou para o envio a especialistas. As espécies foram classificadas em famílias, de acordo com o sistema Angiosperm Phylogeny Group II (APG II, 2003). Os nomes e a autoria das espécies foram conferidos na página eletrônica do Missouri Botanic Garden (http://www.mobot.org).

Os resultados obtidos serão apresentados com as seguintes informações para as espécies: famílias, nomes populares, origem e densidade relativa (Dr). A Dr é a relação percentual entre o número de indivíduos de uma espécie e o número total de indivíduos de todas as espécies (4.493). Procurou-se, sempre que possível, anotar a área de distribuição original das espécies, pesquisa esta dificultada pelo fato de muitas plantas amplamente utilizadas na arborização urbana terem sido distribuídas e plantadas com sucesso em várias localidades no mundo, sem o devido registro de origem.

\section{RESULTADOS E DISCUSSÃO}

A análise florística mostrou elevada riqueza em espécies, os 4.493 indivíduos incluídos no levantamento distribuíram-se em 35 famílias, 92 gêneros e 118 espécies (Tabela 1).

TABELA 1 - Densidade relativa de espécies incluídas no inventário em 10 superquadras residenciais no Plano Piloto de Brasília arborizadas na década de 60.

TABLE 1 - Relative density of species listed in the inventory of 10 residential superblocks in Brasilia's Pilot Plan - trees planted in the 1960s.

\begin{tabular}{llllc}
\hline Famílias & Espécies & $\begin{array}{l}\text { Nomes } \\
\text { populares }\end{array}$ & Origem & Dr \\
\hline Anacardiaceae & Mangifera indica L. & Mangueira & E & $\begin{array}{c}8,30 \\
\text { Continua... }\end{array}$
\end{tabular}




\begin{tabular}{|c|c|c|c|c|}
\hline Famílias & Espécies & $\begin{array}{l}\text { Nomes } \\
\text { populares }\end{array}$ & Origem & $\mathrm{Dr}$ \\
\hline Bignoniaceae & $\begin{array}{l}\text { Spathodea campanulata } \\
\text { Beauv. }\end{array}$ & Xixi-de-macaco & $E$ & 8,00 \\
\hline Fabaceae-Caes. & Caesalpinia pluviosa DC. & Sibipiruna & $\mathrm{Ma}$ & 7,20 \\
\hline Fabaceae-Caes. & $\begin{array}{l}\text { Peltophorum dubium (Spreng.) } \\
\text { Taub. }\end{array}$ & Cambuí & $\mathrm{C}, \mathrm{Cd}$ & 6,30 \\
\hline Myrtaceae & $\begin{array}{l}\text { Syzygium jambolanum (Lam.) } \\
\text { DC. }\end{array}$ & Jambolão & $E$ & 5,10 \\
\hline Lauraceae & Persea americana Mill. & Abacateiro & $E$ & 4,30 \\
\hline Malvaceae & Ceiba speciosa St. Hill. & Paineira & Ms & 4,00 \\
\hline Bignoniaceae & $\begin{array}{l}\text { Tabebuia ipe (Mart ex K. } \\
\text { Schum.) Standl. }\end{array}$ & Ipê-rosa & $E$ & 3,50 \\
\hline Sapindaceae & Sapindus saponaria L. & Saboneteira & $\mathrm{Mg}, \mathrm{Ms}$ & 3,40 \\
\hline Fabaceae-Caes. & $\begin{array}{l}\text { Caesalpinia leiostachya } \\
\text { (Benth.) Ducke }\end{array}$ & Pau ferro & $\mathrm{Ma}$ & 3,30 \\
\hline Fabaceae-Caes. & $\begin{array}{l}\text { Delonix regia (Bojer ex. Hook.) } \\
\text { Raf. }\end{array}$ & Flamboyant & $E$ & 2,60 \\
\hline Myrtaceae & Psidium guajava L. & Goiabeira & $\mathrm{Mg}$ & 2,40 \\
\hline Fabaceae-Cerc. & Bauhinia blakeana Dunn & Pata-de-vaca & $E$ & 2,30 \\
\hline Bignoniaceae & $\begin{array}{l}\text { Tecoma stans (L.) Juss. ex } \\
\text { Kunth }\end{array}$ & Ipê-de-jardim & $E$ & 2,20 \\
\hline Fabaceae-Caes. & Pterogyne nitens Tul. & Amendoim-bravo & $\mathrm{Cd}, \mathrm{Mg}$ & 2,10 \\
\hline Magnoliaceae & Michelia champaca L. & Magnólia & $\mathrm{E}$ & 1,60 \\
\hline Moraceae & Ficus benjamina L. & Ficus & $E$ & 1,60 \\
\hline Araucariaceae & $\begin{array}{l}\text { Araucaria excelsa (Lamb.) R. } \\
\mathrm{Br} .\end{array}$ & Pinheiro-de-natal & $E$ & 1,50 \\
\hline Moraceae & Morus nigra L. & Amoreira & $E$ & 1,40 \\
\hline $\begin{array}{l}\text { Chrysobalanacea } \\
\text { e }\end{array}$ & Licania tomentosa Benth. & Oiti & $\mathrm{Ca}$ & 1,30 \\
\hline Bignoniaceae & $\begin{array}{l}\text { Handroanthus impetiginosus } \\
\text { (Mart. ex. Dc.) Mattos }\end{array}$ & Ipê-roxo & Ms & 1,20 \\
\hline Fabaceae-Mimo. & Adenanthera pavonina $\mathrm{L}$. & Segawe & $\mathrm{E}$ & 1,20 \\
\hline Fabaceae-Mimo. & $\begin{array}{l}\text { Anadenanthera macrocarpa } \\
\text { (Benth.) Brenan }\end{array}$ & Angico-vermelho & $\begin{array}{l}\mathrm{Cd}, \mathrm{Mg} \\
\mathrm{Ms}\end{array}$ & 1,10 \\
\hline Bignoniaceae & $\begin{array}{l}\text { Handroanthus serratifolius } \\
\text { (Vahl.) S. O. Grose }\end{array}$ & Ipê-amarelo & $\begin{array}{l}\text { Am, C, } \\
\mathrm{Cd}, \mathrm{Mg}, \\
\mathrm{Ms}\end{array}$ & 1,10 \\
\hline Meliaceae & Swietenia macrophylla King. & Mogno & Am & 1,10 \\
\hline Fabaceae-Cerc. & Bauhinia variegata $L$. & Pata-de-vaca & $E$ & 1,00 \\
\hline Malvaceae & Pachira aquatica Aubl. & Monguba & Am & 1,00 \\
\hline Fabaceae-Caes. & Caesalpinia echinata Lam. & Pau-brasil & Ma & 0,90 \\
\hline Anacardiaceae & Tapirira guianensis Aubl. & Pombeiro & $\mathrm{Mg}$ & 0,80 \\
\hline Fabaceae-Caes. & Holocalyx glaziovii Taub & $\begin{array}{l}\text { Alecrim de } \\
\text { campinas }\end{array}$ & $\mathrm{Ma}$ & 0,80 \\
\hline Melastomataceae & Tibouchina candolleana Cogn. & Quaresmeira & $\mathrm{Mg}$ & 0,80 \\
\hline Bignoniaceae & $\begin{array}{l}\text { Handroanthus roseo-albus } \\
\text { (Ridley) Mattos }\end{array}$ & Ipê-branco & $\mathrm{Mg}, \mathrm{Ms}$ & 0,80 \\
\hline
\end{tabular}




\begin{tabular}{|c|c|c|c|c|}
\hline Famílias & Espécies & $\begin{array}{l}\text { Nomes } \\
\text { populares }\end{array}$ & Origem & $\mathrm{Dr}$ \\
\hline Fabaceae-Papi. & Tipuana tipu (Benth.) Kuntze & Tipuana & $\mathrm{E}$ & 0,70 \\
\hline Myrtaceae & Eugenia uniflora L. & Pitangueira & $\mathrm{Ma}, \mathrm{Mg}$ & 0,70 \\
\hline Rutaceae & Citrus limon (L.) Burm. F & Limoeiro & E & 0,70 \\
\hline Fabaceae-Caes. & $\begin{array}{l}\text { Shizolobium parahyba (Vell.) S. } \\
\text { F. Blake }\end{array}$ & Guapuruvu & Ma & 0,60 \\
\hline Moraceae & Artocarpus integrifolia L. f. & Jaqueira & E & 0,60 \\
\hline Bignoniaceae & $\begin{array}{l}\text { Handroanthus chrysotrichus } \\
\text { (Mart. ex. A. DC.) Mattos }\end{array}$ & Ipê-amarelo & $\begin{array}{l}\mathrm{C}, \mathrm{Mg} \\
\mathrm{Ma}, \mathrm{Ms}\end{array}$ & 0,60 \\
\hline Moraceae & Ficus sp. & Gameleira & $\mathrm{E}$ & 0,50 \\
\hline Meliaceae & Melia azedarach L. & Cinamomo & $E$ & 0,50 \\
\hline Anacardiaceae & Schinus terebinthifolius Raddi. & Aroeira-vermelha & Ms & 0,50 \\
\hline Rosaceae & $\begin{array}{l}\text { Eriobotrya japonica (Thunb.) } \\
\text { Lindl. }\end{array}$ & Nêspera & $E$ & 0,50 \\
\hline Bignoniaceae & Jacaranda mimosifolia D. Don. & $\begin{array}{l}\text { Jacarandá- } \\
\text { mimoso }\end{array}$ & & 0,50 \\
\hline Cupressaceae & Cupressus sempervirens L. & Cipreste & $\mathrm{E}$ & 0,40 \\
\hline Fabaceae-Mimo. & $\begin{array}{l}\text { Piptadenia gonoacantha (Mart.) } \\
\text { J. F. Macbr. }\end{array}$ & Pau-jacaré & $\mathrm{Mg}, \mathrm{Ms}$ & 0,40 \\
\hline Polygonaceae & Triplaris brasiliana Cham. & Pau-formiga & $\mathrm{Mg}$ & 0,40 \\
\hline Combretaceae & Terminalia catappa L. & Amendoeira & $\mathrm{E}$ & 0,30 \\
\hline Fabaceae-Papi. & Myroxylon peruiferum L. f. & Bálsamo & $\mathrm{Mg}, \mathrm{Ms}$ & 0,30 \\
\hline Anacardiaceae & Anacardium occidentale L. & Cajueiro & C & 0,30 \\
\hline Pinaceae & Pinus caribaea Morelet & Pinheiro & $E$ & 0,30 \\
\hline Polygonaceae & Triplaris pachau Mart. & Pajeú & $E$ & 0,30 \\
\hline Rutaceae & Citrus sinensis (L.) Osbeck & Laranjeira & $E$ & 0,30 \\
\hline Fabaceae-Caes. & $\begin{array}{l}\text { Caesalpinia tinctoria (Kunth) } \\
\text { Benth. ex Reiche }\end{array}$ & Falso-pau-brasil & $E$ & 0,30 \\
\hline Rubiaceae & Genipa americana L. & Jenipapo & $\begin{array}{l}\text { Ma, Mg, } \\
\text { Ms }\end{array}$ & 0,30 \\
\hline Anacardiaceae & $\begin{array}{l}\text { Myracrodruon urundeuva Fr. } \\
\text { All. }\end{array}$ & Aroeira & $\begin{array}{l}\text { C, Cd, } \\
\text { Ms }\end{array}$ & 0,20 \\
\hline Araliaceae & $\begin{array}{l}\text { Schefflera actinophylla (Endl.) } \\
\text { Harms. }\end{array}$ & Guarda-sol & $\mathrm{E}$ & 0,20 \\
\hline Clusiaceae & Calophyllum brasiliensis Camb. & Landim & $\begin{array}{l}\mathrm{Am}, \mathrm{Ma}, \\
\mathrm{Mg}\end{array}$ & 0,20 \\
\hline Euphorbiaceae & Aleurites moluccana ( L.) Wild. & Nogueira & $\mathrm{E}$ & 0,20 \\
\hline Fabaceae-Caes. & $\begin{array}{l}\text { Caesalpinia ferrea Mart. ex Tul. } \\
\text { var. ferrea }\end{array}$ & Jucá & Ma & 0,20 \\
\hline Myrtaceae & Eugenia jambos L. & Jambo amarelo & $E$ & 0,20 \\
\hline Anacardiaceae & Schinus molle L. & Falso-chorão & $\mathrm{Mg}$ & 0,20 \\
\hline Fabaceae-Caes. & $\begin{array}{l}\text { Cassia multijuga (Rich.) Irwin et } \\
\text { Barn }\end{array}$ & Chuva-de-ouro & $\mathrm{E}$ & 0,20 \\
\hline Fabaceae-Papi. & Erythrina falcata Benth. & Mulungu & Ms & 0,20 \\
\hline Lecythidaceae & Cariniana estrellensis (Raddi) & Jequitibá & $\mathrm{Ma}, \mathrm{Mg}$ & 0,20 \\
\hline
\end{tabular}


Kuntze

Ms

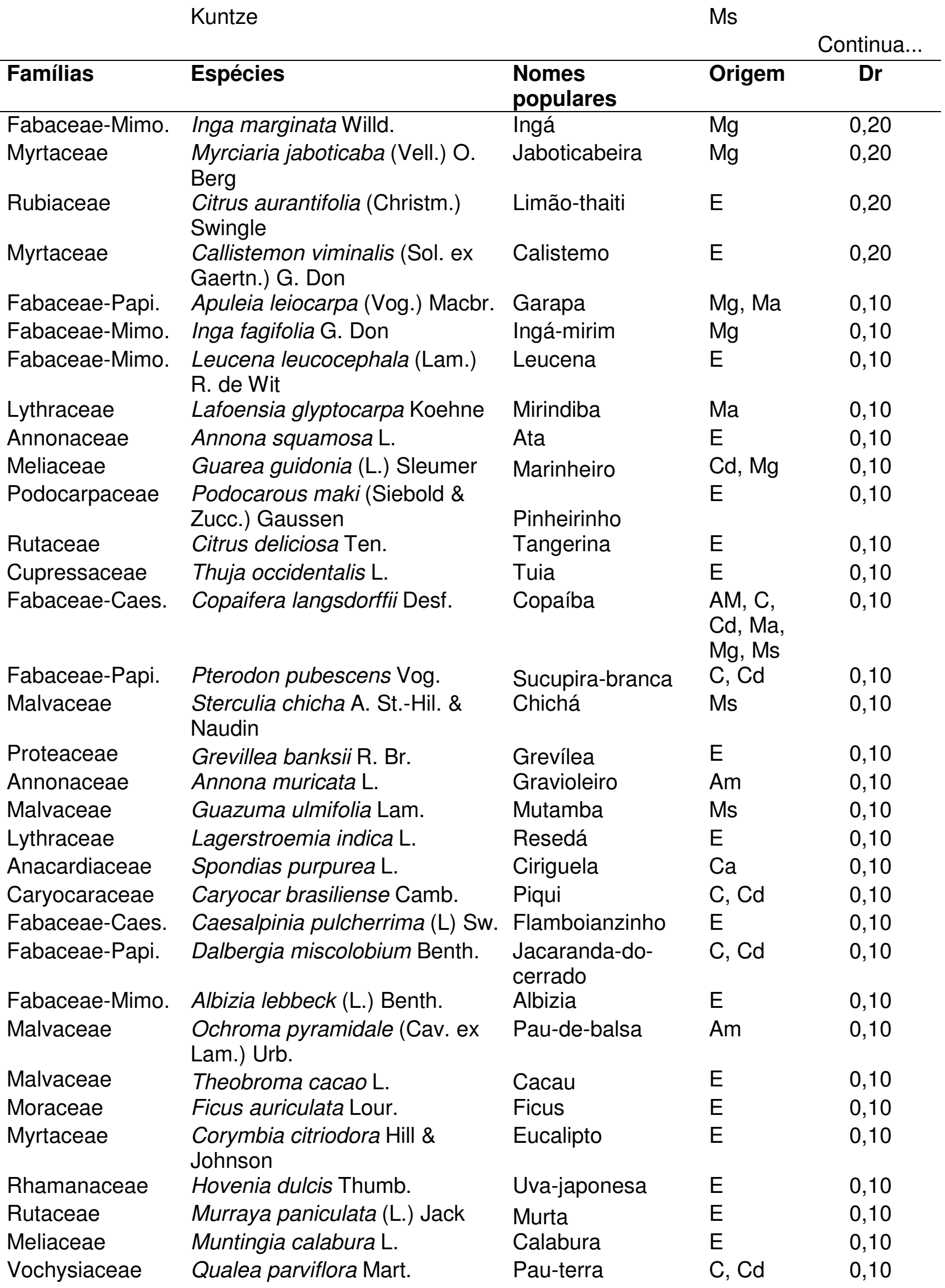


Continua...

\begin{tabular}{|c|c|c|c|c|}
\hline Famílias & Espécies & $\begin{array}{l}\text { Nomes } \\
\text { populares }\end{array}$ & Origem & $\mathrm{Dr}$ \\
\hline Araucariaceae & $\begin{array}{l}\text { Araucaria angustifolia (Bert.) } \\
\text { Kuntze }\end{array}$ & Pinheiro-brasileiro & $\mathrm{Ma}$ & 0,10 \\
\hline Boraginaceae & $\begin{array}{l}\text { Cordia trichotoma (Vell.) Arrab. } \\
\text { Ex steud. }\end{array}$ & Freijó & $\mathrm{Mg}, \mathrm{Ms}$ & 0,10 \\
\hline Clusiaceae & Garcinia cochinchinrnsis Choisy & Falso-mangustão & $E$ & 0,10 \\
\hline Euphorbiaceae & Euphorbia tirucalli $\mathrm{L}$. & Avelós & $E$ & 0,10 \\
\hline Euphorbiaceae & $\begin{array}{l}\text { Hevea brasiliensis (Willd. ex A. } \\
\text { Juss.) M. Arg. }\end{array}$ & Seringueira & Am & 0,10 \\
\hline Fabaceae-Caes. & Cassia grandis L. f. & Cássia-rosa & $E$ & 0,10 \\
\hline Fabaceae-Caes. & $\begin{array}{l}\text { Hymenaea stigonocarpa Mart. } \\
\text { ex Hayne }\end{array}$ & Jatobá-do-campo & & 0,10 \\
\hline Fabaceae-Caes. & Tamarindus indica L. & Tamarindo & $E$ & 0,10 \\
\hline Fabaceae-Mimo. & Acacia mearnsi De Willd. & Acácia-negra & $E$ & 0,10 \\
\hline Fabaceae-Mimo. & $\begin{array}{l}\text { Enterolobium contortisiquum } \\
\text { (Vell.) Morong. }\end{array}$ & Tamboril & Ms & 0,10 \\
\hline Lecythidaceae & Lecythis pisonis Camb. & Sapucaia & $\mathrm{Am}, \mathrm{Mg}$ & 0,10 \\
\hline Lythraceae & Lafoensia pacari A. St. Hil. & Pacari & C & 0,10 \\
\hline Malvaceae & Pseudobombax sp. & & & 0,10 \\
\hline Myrtaceae & $\begin{array}{l}\text { Syzygium malaccense (L.) } \\
\text { Merr. \& L. M. Perry }\end{array}$ & Jambo-vermelho & $E$ & 0,10 \\
\hline Nyctaginaceae & Guapira noxia (Netto) Lundell & Caparosa & C & 0,10 \\
\hline Oxalidaceae & Averrhoa carambola L. & Carambola & $E$ & 0,10 \\
\hline Rutaceae & Citrus bergamia Risso & Bergamota & $E$ & 0,10 \\
\hline Rutaceae & Citrus reticulata Blanco & Tangerina & $E$ & 0,10 \\
\hline Rutaceae & Esenbeckia leiocarpa Engl. & Guarantã & $\mathrm{Mg}$ & 0,10 \\
\hline Urticaceae & $\begin{array}{l}\text { Cecropia adenopus Mart. ex } \\
\text { Miq. }\end{array}$ & Imbaúba & $\mathrm{Mg}$ & 0,10 \\
\hline
\end{tabular}

Onde: Caes. - Caesalpinioideae, Cerc. - Cerciideae, Mimo - Mimosoideae, Papi. - Papilionoideae, Am - Amazônia, C - Cerrado em sentido restrito, $\mathrm{Ca}$ - Caatinga, Cd - Cerradão, E - Exótica, Mg Mata de Galeria, Ma - Mata Atlântica, Ms - Matas Secas, e Dr - Densidade Relativa.

Com $33(27,5 \%)$ espécies, Fabaceae foi a família mais representativa somando 1.472 indivíduos ou $32,7 \%$ do total inventariado. Verificou-se o predomínio de algumas espécies como Caesalpinia pluviosa com 322 (7,17\%) dos indivíduos e Peltophorum dubium com $283(6,30 \%)$ exemplares.

Fabaceae é considerada a família mais rica e abundante nas florestas da América do Sul (HUECK, 1972), assim como no Distrito Federal e sua região do entorno, tendo Silva Júnior et al. (2001) e Nunes et al. (2002) destacado sua importância nas matas de galeria e no cerrado sentido restrito no Distrito Federal, respectivamente. A relativa facilidade na obtenção de mudas por meio de suas sementes que, via de regra, necessitam apenas de tratamento de quebra de dormência tegumentar, e o crescimento relativamente rápido em 
meio urbano (JACINTO, 2001) justificam a maior importância desta família na arborização do Plano Piloto. Cabe também destacar o potencial ornamental de muitas de suas espécies que exibem floração vistosa.

Outras famílias com destaque foram Bignoniaceae com oito espécies (6,66\%) e 801 $(17,82 \%)$ árvores e Anacardiaceae que contribuiu com sete (5,83\%) espécies e 464 indivíduos (10,3\%). Em seguida aparecem Myrtaceae, oito espécies (6,66\%) e 398 (8,86\%) árvores e Malvaceae com cinco espécies (4,16\%) e 234 (5,20\%) indivíduos.

Estas cinco famílias somaram $13,15 \%$ do quantitativo final, estavam presentes nas 10 quadras e contribuíram com $3.196(71,1 \%)$ do total dos indivíduos. As outras 30 famílias contribuíram com $1.298(28,9 \%)$ indivíduos, dentre as quais 18 (47,4\%) famílias apresentaram uma única espécie.

Os gêneros mais ricos foram Caesalpinia e Citrus, ambos com seis espécies, seguidos por Ficus e Cassia com quatro e três espécies respectivamente. A maioria dos gêneros, 73 ou $80,21 \%$ do total, apresentou apenas uma espécie, característica que contribuiu para a elevada riqueza encontrada na arborização do Plano Piloto.

A partir dos dados obtidos no levantamento realizado nas dez superquadras estudadas, foi possível constatar que as dez espécies com maior número de indivíduos foram Mangifera indica* (Mangueira) com 371 árvores, ou 8,26\% do total inventariado, seguida de Spathodea campanulata* (Xixi-de-macaco) com 360 (8,01\%); Caesalpinia pluviosa* (Sibipiruna) com 322 (7,17\%); Peltophorum dubium (Cambuí) com 283 (6,3\%); Syzygium jambolanum* (Jambolão) com 230 (5,12\%); Persea americana* (Abacateiro) com 191 (4,25\%), Ceiba speciosa (Paineira) com 179 (3,98\%); Tabebuia ipe* (Ipê-rosa) com 159 (3,54\%); Sapindus saponaria (Saboneteira) com 154 (3,43\%) e Caesalpinia leiostachya* (Pau-ferro) com 150 árvores (3,34\%). Destas, as sete espécies marcadas com *, são exóticas ao cerrado e somaram 39,6\% dos 4.093 indivíduos plantados na década de 60 (Figura 2). 


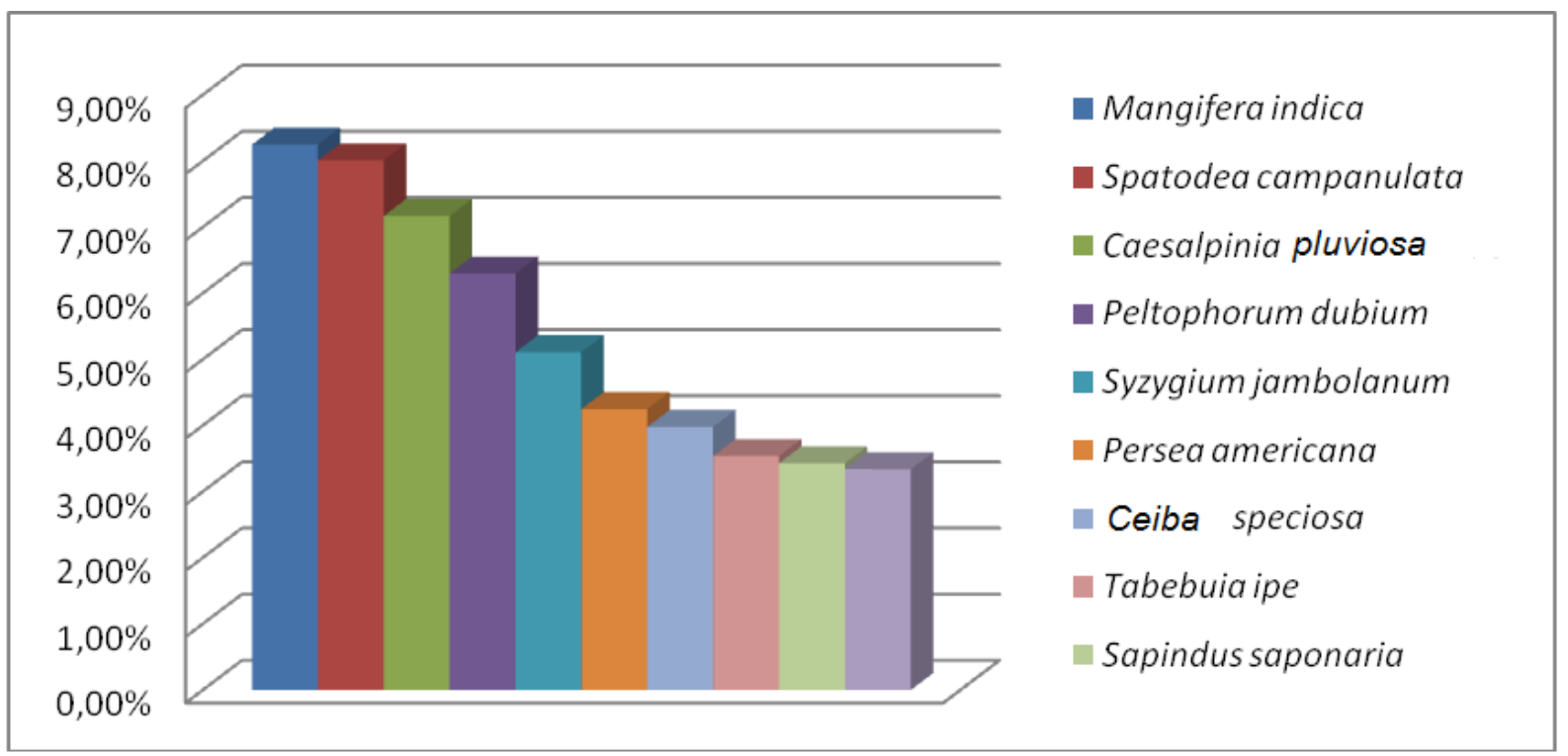

FIGURA 2 - As 10 espécies mais utilizadas na arborização urbana no Plano Piloto de Brasília na década de 60 (1960-1969).

FIGURE 2 - The 10 most used species in the urban forestry of Brasilia's Pilot Plan, in the 1960s (1960-1969).

Dentre as 48 espécies que apresentaram cinco ou menos indivíduos no censo figuram Qualea grandiflora (Pau-terra-grande) com 5 (0,11\%), Pterodon pubescens (Sucupira-branca) $4(0,1 \%)$, Caryocar brasiliense (Piqui) $3(0,1 \%)$, Qualea parviflora (Pauterra-da-folha-miúda), Dalbergia miscolobium (Jacarandá-do-cerrado) 2 (0,04\%) e Guapira noxia (Caparosa), Hymenaea stigonocarpa (Jatobá-do-cerrado), Lafoensia pacari (Pacari), todas com um único indivíduo $(0,02 \%)$ (Tabela 1$)$. Estas são espécies remanescentes do cerrado sentido restrito, vegetação original na área de implantação do Plano Piloto. Sua baixa representação no computo geral de indivíduos demonstra a ampla retirada da vegetação nativa para a implantação da nova capital.

Através do presente inventário constatou-se que a espécie com maior número de indivíduos plantados na década de 60 foi Mangifera indica (Mangueira), família Anacardiaceae, com 371 (8,26\%) indivíduos (Tabela 1). A mangueira é árvore exótica, originária da Índia e vizinhanças, com copa larga e frutos carnosos e bastante corriqueira nas áreas verdes públicas e particulares da capital. Durante todo o ano a população se beneficia da espécie pela sombra proporcionada, ou, no início do período das chuvas, pelos seus frutos. No entanto, o acúmulo de frutos nas calçadas acaba por tornar a caminhada perigosa pelo risco de quedas. Outra situação observada por Bredt, (2001), é que tanto a Mangueira quanto o Jambolão servem como fonte de alimento e abrigo noturno $(23,4 \%$ e 
18,9\%) para o morcego Artibeus lituratu. Pelo fato das árvores estarem plantadas próximas aos edifícios residenciais, a população de morcegos ocasiona incômodos, agressões e mordidas acidentais na comunidade e animais de estimação. Segundo sugestão da autora, o plantio das espécies arbóreas que são fontes de alimento para os morcegos devem ocorrer em áreas afastadas das residências e/ou das vias de circulação de pedestres a fim de minimizar os transtornos.

Spathodea campanulata, o Xixi-de-macaco, da família Bignoniaceae, foi outra espécie amplamente utilizada na década de 60 . Sua bela floração e rápido crescimento foram os maiores atrativos para sua implantação em Brasília. Esta espécie de origem africana mostrou-se após alguns anos de convivência desvantagens que a tornaram cada vez menos utilizada no Plano Piloto. Segundo Machado et al., 1992, os primeiros exemplares plantados na cidade apresentaram envelhecimento precoce, com alta taxa de mortalidade. Suas flores grandes e alaranjadas, produzidas em grande quantidade, principalmente quando plantadas em pequenos maciços, se acumulam no solo que se torna escorregadio e perigoso para pedestres.

A Sibipiruna, Caesalpinia pluviosa, foi a espécie de Fabaceae mais plantada na década de 60, apresentando 322 (7,2\%) exemplares. Em avaliação realizada por Ribeiro et al. (2006), em Vinhedo, SP, a Sibipiruna foi a terceira espécie de maior abundância. A Sibipiruna, originária da Mata Atlântica, apresenta bela floração, facilidade de obtenção de sementes e produção de mudas, teve ampla utilização na arborização em vários estados brasileiros (LORENZI, 1992). Em Brasília foi largamente plantada no período inicial da arborização no Plano Piloto. Entretanto, a partir da década de 90 constatou-se elevada mortalidade de indivíduos jovens e adultos, desta forma, seu plantio foi então reduzido (MACHADO et al., 1992).

Já o Cambuí, Peltophorum dubium, com 283 (6,30\%) indivíduos, vem sendo amplamente plantado desde então. Por ser espécie nativa que coloniza matas secas e bordas de matas de galeria é rústica e de rápido crescimento, muito usada em paisagismo, pois proporciona ótima sombra (LORENZI, 1992) e bela floração amarela. Em Brasília seu comportamento após o plantio foi considerado bom (MACHADO et al., 1992).

Nas dez superquadras estudadas, foram contabilizadas 230 árvores $(5,12 \%)$ de Jambolão, Syzygium jambolanum. Esta é espécie exótica originária da Ásia, da família Myrtaceae, e foi amplamente plantada no DF pela extinta PROFLORA (Companhia de Reflorestamento de Brasília) em extensas áreas que formaram o cinturão verde implantado para conter a invasão de áreas públicas. Seus frutos carnosos são dispersos por aves o que

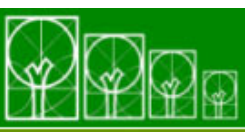

$\mathbf{S} \cdot \mathbf{B} \cdot \mathbf{A} \cdot \mathbf{U}$ Soc. Bras. de Arborização Urbana 
facilitou a sua invasão em matas de galeria no DF. Em muitos locais o Jambolão foi plantado ao longo das calçadas para propiciar sombra. Entretanto, após frutificação abundante seus frutos se acumulam e tornam as calçadas escorregadias para pedestres.

A Paineira, Ceiba speciosa (Malvaceae) é espécie nativa em matas secas no Brasil Central. No ambiente urbano do Plano Piloto apresenta rápido crescimento e floração espetacular. Seu tronco abaulado e com acúleos, é característica marcante da espécie que também se tornou bastante conhecida entre os habitantes como barriguda. A frutificação produz grande quantidade de paina o que facilita a dispersão das sementes pelo vento.

De modo geral as espécies encontradas em maiores quantidades nas superquadras estudadas foram aquelas usadas na implantação da cinta arbórea, sugerida por Lúcio Costa. A proposta incluiu um cinturão verde composto de espécie única com o propósito de facilitar a identificação das superquadras. Muitas destas cintas compuseram verdadeiras monoculturas de árvores. Atualmente estas cintas estão desfiguradas pela elevada mortalidade de árvores ocorrida na década de 70 , em parte pela facilitação da propagação de pragas e doenças e em parte pela má adaptação de espécies exóticas. Em algumas superquadras a sobrevivência destas cintas foi adequada o que resultou no aumento do quantitativo da espécie plantada no resultado final.

\section{CONCLUSÕES}

A arborização urbana realizada na década de 60 no Plano Piloto apresentou elevada diversificação de espécies plantadas. Os 4.493 indivíduos inventariados distribuíram-se em 35 famílias, 92 gêneros e 118 espécies. Foi constatada a predominância de espécies exóticas em relação às nativas remanescentes ou reintroduzidas.

De modo geral as espécies plantadas, originárias do bioma Cerrado, são típicas das matas de galeria ou matas estacionais. A maior facilidade da coleta e produção de mudas em viveiro devido e/ou o maior porte e mais rápido desenvolvimento das espécies das matas em relação às espécies do cerrado sentido restrito, aparentemente, direcionaram as decisões do Departamento de Parques e Jardins (DPJ-DF) quanto à seleção das espécies para plantio no Plano Piloto.

O estudo, ao descrever as quantidades e identificar as espécies de árvores nativas e exóticas encontradas no Plano Piloto, valoriza a exuberante arborização existente na cidade, e apóia e sugere a estratégia da substituição contínua das espécies exóticas por espécies nativas.

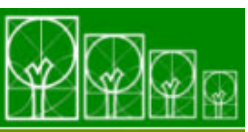

$\mathbf{S} \cdot \mathbf{B} \cdot \mathbf{A} \cdot \mathbf{U}$ Soc. Bras. de Arborização Urbana 
Cabe ressaltar que a vegetação original na área de implantação do Plano Piloto foi o cerrado sentido restrito e o cerradão cujas espécies nativas deveriam ser preservadas, quando já existirem nos sítios, e, priorizadas em plantios futuros. Atualmente a germinação de boa parte das espécies arbóreas nativas destas comunidades é conhecida, o que facilitará esta nova empreitada.

\section{REFERÊNCIAS BIBLIOGRÁFICAS}

ALENCAR, F. O. C. C., LIMA. S. C. O. Histórico do Verde de Brasília. In: ENCONTRO NACIONAL DE ARBORIZAÇÃO URBANA, 9, 2001, Brasília, DF. Resumos... Brasília, DF: [s.n.], 2001. 8p.

ANGIOSPERM PHYLOGENY GROUP (APG). An update of the angiosperm phylogeny group classification for the orders and families of flowering plants: APG II. Botanical Journal of the Linnean Society, v. 141, n. 4, p. 399-436, 2003.

BREDT A. Morcegos fitófagos e a arborização de Brasília. In: ENCONTRO NACIONAL DE ARBORIZAÇÃO URBANA, 9, 2001, Brasília, DF. Resumos... Brasília, DF: [s.n.], 2001.

CÉSAR, L. P. de M. Visões do mundo e modelos de paisagismo: ecossistemas urbanos e utilização de espaços livres em Brasília. 2003. 250p. Tese de Doutorado, Universidade de Brasília, Brasília.

FERRARA, L. A.. Os significados urbanos. Edusp, São Paulo, 2000.192p.

GONZÁlES, S. RODRIGUES M. das G. R.; ALENCAR, F. O. C.C. de; LIMA FILHO, R. M.; FARIAS NETO, P. \& MARTINS J. L.. Seleção e introdução de novas espécies arbóreas para utilização na área urbana do Distrito Federal, no Período de 1988 a 1998. In: ENCONTRO NACIONAL DE ARBORIZAÇÃO URBANA, 9.,2001, Brasília, DF. Resumos. Brasília, DF: [s.n.], 2001.

HUECK, K. As florestas da América do Sul. Ecologia, composição e importância econômica. Editora da Universidade de Brasília \& Editora Polígono, São Paulo, 1972. $465 p$.

JACINTO, J. M. de M. Análise silvicultural urbana de seis espécies florestais utilizadas na arborização de Brasília. 2001. 65f. Dissertação (Mestrado em Ciências Florestais) Universidade de Brasília, Brasília.

KURIHARA, D. L., ENCINAS, J. I., PAULA, J. E. Levantamento da arborização do Campus da Universidade de Brasília. Revista Cerne, Lavras, v. 11,n. 2, p127-136, abr./jun. 2005. 
LIMA, S. C.. Arborização urbana de Brasília - Contribuição ao estudo de seu processo. 2003. 175f. Dissertação (Mestrado em Arquitetura e Urbanismo), Universidade de Brasília.

LORENZI, H.. Árvores brasileiras: manual de identificação e cultivo de plantas arbóreas nativas do Brasil. Nova Odessa: Plantarum, 1992. 382p.

MACHADO, J. W. B., ALENCAR, F. O. C. C., RODRIGUES, M. G. R.. Árvores de Brasília. GDF, Brasília, 1992.89p.

MILANO, M. S. Métodos de amostragem para avaliação de ruas. In: Congresso Brasileiro de Arborização Urbana 2, 1994, São Luiz, MA. Resumos... São Luiz, MA, 1994.

NUNES, R. V.; SILVA JÚNIOR, M. C.; FELFILI, J. M.; WALTER, B. M. T. Intervalos de classe para a abundância, dominância e freqüência do componente lenhoso do cerrado sentido restrito no Distrito Federal. Revista. Árvore, v. 26, n. 2, p.173-182, 2002.

RIBEIRO, R. C. S., HARDER, I. C. F., TAVARES, A. R. Avaliação qualitativa e quantitativa da arborização das praças de Vinhedo, SP. Revista Brasileira de Horticultura Ornamental, Campinas, v.12,n2., p.75-87,2006.

RIBEIRO, J. F. \& WALTER, B. M. T. Fitofisionomias do Bioma Cerrado. In: SANO, S. M.; Almeida, S.P (Org.) Cerrado: ecologia e flora. Planaltina, EMBRAPA-CPAC., 2008. $556 p$.

ROCHA, R. T., LELES, P. S. S., OLIVEIRA NETO, S. N. Arborização de vias púbicas em Nova Iguaçu, RJ: o caso dos bairros Rancho Novo e Centro. Rev. Árvore, Viçosa, vol.28, no.4, p. 599-607, julho-agosto. 2004.

ROMERO, M. A. B.. Planejamento de Brasília. In: ENCONTRO NACIONAL DE ARBORIZAÇÃO URBANA, 9., 2001, Brasília, DF. Resumos... Brasília, DF: [s.n.], 2001. $9 p$.

SENNA, D., DEUSDARÁ FILHO, R., PEREIRA, H.S. Arboles fuera del bosque - país: Brasil. FAO/MMA, Brasília, 2001. 13p.

SILVA, A. G., GONÇALVES, W., PAIVA, H. N. Avaliando a arborização urbana. Viçosa: Aprenda Fácil, 2007. 346p.

SILVA, A. S. da. Arborização urbana de Brasília: da concepção de Lúcio Costa e da configuração atual. 2003. 101f. Dissertação (Mestrado em Arquitetura e Urbanismo), Universidade de Brasília, Brasília.

SILVA JÚNIOR, M. C., BATISTA L. S., CALDAS L. S. Arborização e corredores ecológicos no Distrito Federal. In: Encontro Nacional de Arborização Urbana. Brasília,9, Brasília, 2001. Resumos... Brasília, DF: [s.n.], 2001. 9p.

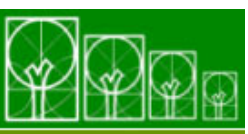

$\mathbf{S} \cdot \mathbf{B} \cdot \mathbf{A} \cdot \mathbf{U}$ Soc. Bras. de Arborização Urbana 
SPIRN, A. W. O jardim de granito: a natureza no desenho da cidade. EDUSP, São Paulo,1995. 329p.

TEIXEIRA NETO, T.G. \& RODRIGUES, M. das G.R. Estudos preliminares com a Cassia siamea Lam. no Distrito Federal. Cerrado, Brasilia, v.7, n.30, p.8-14. 1975.

UNESCO. Vegetação no Distrito Federal - tempo e espaço.- 2 ed. UNESCO, Brasília, 2002.80p. 